\begin{tabular}{|c|c|}
\hline Title & Cs Beta with an A I-rich composition as a highly active base catalyst for Knoevenagel condensation \\
\hline Author(s) & Otomo, Ryoichi; Osuga, Ryota; Kondo, Junko N.; Kamiya, Y uichi; Y okoi, Toshiyuki \\
\hline Citation & $\begin{array}{l}\text { A pplied catalysis A-general, } 575,20-24 \\
\text { https://doi.org/10.1016/.apcata.2019.02.014 }\end{array}$ \\
\hline Issue Date & $2019-04-05$ \\
\hline Doc URL & http:/hdl .handle.net/2115/80825 \\
\hline Rights & $\begin{array}{l}\text { @ 2019. This manuscript version is made available under the CC-BY-NC-ND } 4.0 \text { license } \\
\text { http://creativecommons.org/icenses/by-nc-nd/4.0/ }\end{array}$ \\
\hline Rights(URL) & https://creativecommons.org/icenses/by-nc-nd/4.0/ \\
\hline Type & article (author version) \\
\hline File Information & 190206-A lkali-Text-OR.pdf \\
\hline
\end{tabular}

Instructions for use 


\section{Cs-Beta with an Al-rich composition as a highly active base catalyst}

\section{for Knoevenagel condensation}

6 Ryoichi Otomo, ${ }^{\mathrm{a}, \mathrm{b}, *}$ Ryota Osuga, ${ }^{\mathrm{a}}$ Junko N. Kondo, ${ }^{\mathrm{a}}$ Yuichi Kamiya, ${ }^{\mathrm{b}}$ and Toshiyuki

anstitute of Innovative Research, Tokyo Institute of Technology, 4259 Nagatsuta, Midori10 ku,Yokohama 226-8503, Japan.

$11{ }^{b}$ Faculty of Environmental Earth Science, Hokkaido University, Nishi 5, Kita 10, Kita-ku, Sapporo, 12 060-0810, Japan ${ }^{c}$ PRESTO, JST, 4259 Nagatsuta, Midori-ku,Yokohama 226-8503, Japan

16 Corresponding author:

$17 *$ Dr. Ryoichi Otomo

18 Tel: +81-11-706-2259, E-mail: otomo@ees.hokudai.ac.jp

19 * Dr. Toshiyuki Yokoi

20 Tel: +81-45-924-5265, E-mail: yokoi@cat.res.titech.ac.jp 


\section{Abstract}

Ion-exchange of an Al-rich zeolite beta, synthesized by organic structure-directing agent-

free method (Beta-OF), was studied for application as a base catalyst. While the as-synthesized Beta-

4 OF in Na-form itself had base sites and showed moderate catalytic activity for Knoevenagel

5 condensation, the ion-exchange with $\mathrm{Cs}^{+}$improved the catalytic activity. For Knoevenagel

6 condensation of benzaldehyde with ethyl acetoacetate, the catalytic activity of Beta-OF ion-

7 exchanged with $\mathrm{Cs}^{+}$largely surpassed that of the conventional zeolite beta with less $\mathrm{Al}$ content. $\mathrm{CO}_{2-}$

8 TPD and IR observation with chloroform as a probe molecule revealed that the Cs-exchanged Beta-

9 OF had strong base sites comparable to Cs-exchanged Y zeolite. Base strength of Beta-OF was

10 stronger than that expected by Sanderson's theory. A local high density of Al atoms in the framework

11 of Beta-OF resulted in the unexpected base property and high catalytic activity.

13 Keywords: Beta; Ion exchange; Knoevenagel condensation; OSDA-free; Solid base 


\section{Introduction}

Zeolite beta, with the three-dimensional large pore system, has been well studied and practically used

as solid acid catalysts in chemical industies. The conventional synthesis of zeolite beta requires organic structure-directing agent (OSDA), typically tetraethylammonium hydroxide, the use of which unfortunately results in high synthetic cost of the zeolite, $\mathrm{CO}_{2}$ and $\mathrm{NO}_{\mathrm{x}}$ emission, and energy consumption. The recent breakthrough is the successful synthesis of zeolite beta without using any OSDA [1-4]. This sustainable and feasible synthesis method has led us into the extensive research on “OSDA-free” zeolite beta (hereinafter, referred to as "Beta-OF”) relevant to solid acid catalysts for cracking of hydrocarbons [5-8], Friedel-Crafts reactions [9,10], methanol to olefins reaction [11], and conversion of sugars [12].

A unique feature of Beta-OF is a high $\mathrm{Al}$ content, which is much higher than the conventional zeolite beta synthesized with OSDAs; a typical Si/Al ratio for Beta-OF ranges from 5 to 8, while that for the conventional beta (Beta-CV) ranges from 10 to 20. Making good use of the high $\mathrm{Al}$ content for Beta-OF, ion-exchange with $\mathrm{Fe}^{2+}$ or $\mathrm{Cu}^{2+}$ has been investigated and the ion-exchanged Beta-OF showed the excellent catalytic perfomance in decomposition of $\mathrm{NO}_{\mathrm{x}}$ and hydrocarbons for purification of automobile exhaust gas [7,13-15].

Generally, zeolites ion-exchanged with alkali metal cations have base properties. In fact, the ion-exchange of faujasite zeolites with high Al contents has been intensively studied because of their high ion-exchange capacities and strong basicity [16-18]. Beta-CV has been studied for the ionexchange with alkali metal cations and application as a base catalyst for Knoevenagel condensation, 
Michael addition and so on [19-21]. However, there are only few reports on the ion-exchange with alkali metal cations and base catalysis for Beta-OF.

In the present study, taking advantage of its high $\mathrm{Al}$ content, Beta-OF was ion-exchanged with various metal cations and used as a solid base catalyst. We found that Cs-exchanged Beta-OF showed an unexpectedly high catalytic performance in Knoevenagel condensation reactions.

\section{Experimental}

\subsection{Synthesis and ion-exchange of Beta-OF}

Beta-OF was synthesized following the reported method [1,5]. The obtained Na-form sample is designated as “Na-Beta-OF”. Sodium cation in Na-Beta-OF was exchanged with $\mathrm{Zn}^{2+}, \mathrm{Ag}^{+}, \mathrm{Cs}^{+}$, and $\mathrm{La}^{3+}$ using $\mathrm{Zn}\left(\mathrm{NO}_{3}\right)_{2}, \mathrm{AgNO}_{3}, \mathrm{CsCl}$, and $\mathrm{La}\left(\mathrm{NO}_{3}\right)_{3}$, respectively. Typically, Na-Beta-OF was soaked into $1 \mathrm{M}$ aqueous solution of metal salts (50 mL/g-zeolite) and the resulting suspension was vigorously stirred at $80{ }^{\circ} \mathrm{C}$ for $1 \mathrm{~h}$. The solid sample was recovered by filtration and dried overnight at $80{ }^{\circ} \mathrm{C}$. For the ion-exchange with $\mathrm{Zn}^{2+}, \mathrm{Cs}^{+}$, and $\mathrm{La}^{3+}$, this operation was repeated two more times in order to increase the ion-exchange degree. Na-Beta-OF was ion-exchanged to ammonium form by stirring the sample powder in $2.5 \mathrm{M} \mathrm{NH}_{4} \mathrm{NO}_{3}$ aqueous solution and calcined at $550{ }^{\circ} \mathrm{C}$ for $5 \mathrm{~h}$ to obtain a proton-form sample. The ion-exchanged samples with the metal cations and proton are designated as i.e. "M-Beta-OF”, where $\mathrm{M}$ is $\mathrm{H}, \mathrm{Zn}, \mathrm{Ag}, \mathrm{Cs}$, and La. As a comparison, the ionexchange with $\mathrm{Cs}^{+}$was conducted on the commercially available conventional $\mathrm{H}$-beta $(\mathrm{Si} / \mathrm{Al}=11.9$, purchased from Zeolyst) and $\mathrm{Na}-\mathrm{Y}(\mathrm{Si} / \mathrm{Al}=2.4$, purchased from Tosoh). These samples are 
designated as Cs-Beta-CV and Cs-Y, respectively.

\subsection{Characterization of samples}

Powder X-ray diffraction (XRD) patterns of the samples were collected on a Rigaku Ultima III diffractometer using a $\mathrm{Cu} \mathrm{K \alpha}$ radiation (40 kV, $20 \mathrm{~mA})$. The amount of $\mathrm{Zn}, \mathrm{Ag}$ and $\mathrm{La}$ in the samples was analyzed by ICP-AES using a Shimadzu ICPE-9000 spectrometer. The amount of Na and Cs in the samples was estimated by atomic absorption spectroscopy (AAS) on a Shimadzu AA6200 spectrometer. Since mass of samples changed due to the introduction of heavy metals and sodium contents in $\mathrm{mmol} / \mathrm{g}$ were unknown, the ion-exchange degree was calculated based on the content of $\mathrm{Al}$ atoms, which are the ion-exchange sites.

Base properties of samples were examined by temperature-programmed desorption of $\mathrm{CO}_{2}$ (CO2-TPD). Sample powder (50 mg) was pretreated at $400{ }^{\circ} \mathrm{C}$ for $1 \mathrm{~h}$ in He flow. The samples was exposed to $\mathrm{CO}_{2}$ flow ( $\left.50 \mathrm{ml} / \mathrm{min}\right)$ at $50{ }^{\circ} \mathrm{C}$ for $0.5 \mathrm{~h}$ and then the gas flow was switched to He for removing weakly adsorbed $\mathrm{CO}_{2}$. TPD profile was obtained by increasing the temperature of the sample from 50 to $400{ }^{\circ} \mathrm{C}$ at the rate of $10{ }^{\circ} \mathrm{C} / \mathrm{min}$ in He flow $(50 \mathrm{ml} / \mathrm{min})$ and effluent gas was analyzed by thermal conductivity detector. Additionally, base properties of Cs-exchanged samples were characterized by FT-IR with chloroform as a probe molecule. Sample powder (50 mg) was pelletized to a self-supporting disk (42 $\pm 2 \mathrm{mg}$ ) and set in a quartz cell connected to a vacuum line.

The sample disk was heated to $400{ }^{\circ} \mathrm{C}$ and kept for $1 \mathrm{~h}$ in vacuo and cooled to $50{ }^{\circ} \mathrm{C}$. Then, the first spectrum was recorded. A pre-determined amount of chloroform was introduced into the cell and after 
the pressure became constant a spectrum was recorded. This operation was repeated as the amount of chloroform was changed at 50, 100, and $200 \mathrm{~Pa}$. Here the difference spectra obtained by subtracting the first spectrum from the spectra after a certain amount of chloroform adsorbed were shown.

\subsection{Catalytic tests}

Catalytic performance of the ion-exchanged samples was assessed in Knoevenagel condensation of benzaldehyde with ethyl cyanoacetate or ethyl acetoacetate (Scheme 1). The sample powder was added to a round-bottom flask and pretreated in vacuo at $400{ }^{\circ} \mathrm{C}$ for $1 \mathrm{~h}$. Then, dried dimethyl sulfoxide solution containing benzaldehyde and either acetate was poured into the flask. The catalytic reaction was conducted under inert nitrogen atmosphere. Small aliquots of the solution was taken at set time points and analyzed by GC-FID equipped with a DB-5 column $(30 \mathrm{~m} \times 0.25$ $\mathrm{mm} \times 0.25 \mu \mathrm{m})$. Since the corresponding ethyl cinnamate esters were the sole products detected for all the reaction runs, catalytic performance was estimated in terms of product yields.

\section{Results and discussion}

\subsection{Structure and composition of Beta-OF samples}

Na-Beta-OF had a highly crystalline *BEA-type structure but the MOR-phase was slightly observed on the XRD pattern (Figure S1). For H- and Zn-Beta-OF samples, the diffraction patterns did not change before and after the ion-exchange. The ion-exchange with $\mathrm{Ag}^{+}, \mathrm{Cs}^{+}$and $\mathrm{La}^{3+}$ resulted in the decrease in the diffraction intensities, while no halo peak was observed. Similar observation 
has been reported on Cs-exchanged faujasite zeolites [22,23]. With reference to these reports, this decrease would be caused by the strong X-ray scattering on these heavy metals, but not by the destruction of the structure.

Table 1 summarizes the composition of the prepared zeolite samples. For all of Beta-OF samples, Si/Al ratio determined by ICP analysis ranged from 5.0 to 5.1, indicating that neither dealumination nor desilication occurred during the ion-exchange procedure. Na-Beta-OF had 2.3 $\mathrm{mmol} / \mathrm{g}$ of $\mathrm{Na}$, which was almost the same as the Al content $(2.2 \mathrm{mmol} / \mathrm{g})$, confirming that the negative charge on its framework was compensated by $\mathrm{Na}^{+}$. After the ion-exchange to ammoniumform and the following calcination to give H-Beta-OF, the Na content was decreased to a negligible amount. Sodium cation was exchanged with $\mathrm{Ag}^{+}$and $\mathrm{Cs}^{+}$at 90 and $80 \%$ of ion-exchange degree, respectively. Since the total mass of the sample changed and the exact amount of exchangeable $\mathrm{Na}^{+}$ was unclear when heavy metals were introduced, the ion-exchange degree was calculated based on the amount of ion-exchangeable $\mathrm{Al}$. The ion-exchange with $\mathrm{Zn}^{2+}$ proceeded at $\sim 70 \%$ of the exchange degree, but $\mathrm{La}^{3+}$ was introduced at only $55 \%$ of the exchange degree. Since ion-exchange with multivalent cations requires neighboring ion-exchange sites, the exchange degree was not increased for $\mathrm{Zn}^{2+}$ and $\mathrm{La}^{3+}$. For $\mathrm{Zn}$ - and La-Beta-OF, total positive charges by $\mathrm{Na}^{+}$and metal cations $\left(\mathrm{Zn}^{2+}\right.$ or $\left.\mathrm{La}^{3+}\right)$ were lower than the $\mathrm{Al}$ content. This shortage of the total positive charge would be compensated by proton, because aqueous solution of zinc or lanthanum nitrate was weakly acidic [24]. 
$\mathrm{mmol} / \mathrm{g}$, which was approximately a half of the amount of $\mathrm{Na}^{+}$cation, indicating that not all the $\mathrm{Na}^{+}$ cation but particular cation formed such base sites that desorb $\mathrm{CO}_{2}$ above $50{ }^{\circ} \mathrm{C}$. The ion-exchange of $\mathrm{Na}^{+}$for $\mathrm{Cs}^{+}$led to enhancement of the basicity; Cs-Beta-OF showed a large desorption peak at $280{ }^{\circ} \mathrm{C}$ and the number of base sites was estimated to be $1.5 \mathrm{mmol} / \mathrm{g}$. Zn- and La-Beta-OF showed a desorption peak at $\sim 120^{\circ} \mathrm{C}$. These samples had $\sim 0.3 \mathrm{mmol} / \mathrm{g}$ of remaining $\mathrm{Na}^{+}$, which could form a part of base sites. H- and Ag-Beta-OF had only a small number of base sites. Ag-Beta-OF showed a small peak at $270{ }^{\circ} \mathrm{C}$, implying the presence of strong base sites, while H-Beta-OF did not show any desorption at high temperature.

\subsection{Catalytic properties of ion-exchanged Beta-OF samples}

Catalytic properties of the ion-exchanged Beta-OF zeolites were studied in Knoevenagel condensation of benzaldehyde with ethyl cyanoacetate (Figure 2). Without a catalyst, only a small amount of ethyl cyanocinnamate was produced. Na-Beta-OF itself acted as a base catalyst promoting the Knoevenagel condensation and gave 39\% yield at $3 \mathrm{~h}$. Note that for all the catalysts, ethyl cyanocinnamate was the sole product detected. Cs-Beta-OF showed the best catalytic performance; the yield of ethyl cyanocinnamate reached $52 \%$ for $3 \mathrm{~h}$. Ag-Beta-OF showed a catalytic performance similar to Na-Beta-OF regardless of the highest the exchange degree. Zn-Beta-OF exhibited a slight catalytic activity; the yield of ethyl cyanocinnamate was about $9 \%$ after 3 h. H-Beta-OF and La-BetaOF did not show any catalytic activity probably because these zeolites with $\mathrm{H}^{+}$and $\mathrm{La}^{3+}$ could act as acid catalysts. 
2 Beta-OF showed a catalytic activity similar to that of Na-Beta-OF in spite of the small number of base sites. In terms of the product yield, the catalytic activity was not correlated with the total number of base sites estimated by $\mathrm{CO}_{2}$-TPD. These three samples commonly showed desorption of $\mathrm{CO}_{2}$ above $200{ }^{\circ} \mathrm{C}$, which implies the presence of strong base sites. Obviously, strong base sites played an important role in promoting the Knoevenagel condensation. On the other hand, weak base sites that were observed in desorption of $\mathrm{CO}_{2}$ below $200^{\circ} \mathrm{C}$ did not contribute to the reaction, probably because they cannot abstract a hydrogen atom at the $\alpha$-position of ethyl cyanoacetate, which is supposed to be the rate-determining step for Knoevenagel condensation. The order of catalytic activity was opposite to that of electronegativity of hydrogen and metal atoms except for lanthanum. The electronegativity is in the order of Cs (2.2) < Na (2.9) < La (3.1) < Ag (4.4) $<$ Zn (4.5) $<\mathrm{H}(7.2)<\mathrm{O}$ (7.5), where the figures in the parentheses are electronegativity values in eV $[25,26]$. It can be considered that a metal species with a low electronegativity could donate electron on the zeolite framework to a high degree and consequently the resulting electronegative framework oxygen atoms would act as base sites promoting the Knoevenagel condensation. The lower electronegativity a metal species has, the stronger base site the neighboring framework oxygen atom forms. This tendency supports the assumption that the catalytic activity was governed by the strength of base sites. Catalytic properties of Cs-Beta-OF was compared with Cs-exchanged Beta-CV, and Y zeolites (Figure 3). Cs-Beta-OF gave a higher yield of ethyl cyanocinnamate than Cs-Beta-CV and 
1 Cs-Y (Figure 3A). The catalytic activity of these samples was further compared for the reaction with

2 ethyl acetoacetate instead of cyanoacetate (Figure 3B). Since the acidity of active methylene for ethyl

3 acetoacetate is lower than that for ethyl cyanoacetate ( $p K a=14.1$ and 13.1, respectively), the

4 reactivity of ethyl acetoacetate was much lower, resulting in the low production rate of ethyl

5 acetylcinnamate [27]. Cs-Beta-OF also showed the highest yield of ethyl acetylcinnamate, being

6 comparable to Cs-Y, which has been well known as a highly active base catalyst [16-18]. Cs-Beta-

7 CV showed poor catalytic activity, resulting in only a slight yield of the product, though it showed

8 moderate catalytic activity for the reaction with ethyl cyanoacetate.

The catalytic activity of these three samples were compared in terms of turnover frequency

(TOF) for the production of the cinnamate esters over $\mathrm{Cs}^{+}$cation (Table 2). Cs-Beta-OF showed

higher TOF than Cs-Y for both of cinnamate esters, suggesting the advantage of Cs-Beta-OF over the

conventional zeolite-based base catalyst. Cs-Beta-CV showed high TOF for the production of ethyl

cyanocinnamate, while it showed much lower TOF for that of ethyl acetocinnamate. Because the

formation of ethyl cyanocinnamate could occur over all the base sites formed by $\mathrm{Cs}^{+}$cation, TOF for

Cs-Beta-OF and Cs-Y was estimated to be low due to their large number of base sites. On the other

hand, the formation of ethyl acetocinnamate requires specifically strong base sites. The high TOF for

Cs-Beta-OF suggest the presence of such strong base sites on it. Cs-Beta-OF showed much higher

catalytic activity than Cs-Beta-CV for ethyl acetocinnamate, indicating the advantage of OSDA-free

beta over the conventional one in terms of not only the synthesis cost and simplicity but also the 

examined by FT-IR using chloroform as a probe molecule (Figure 4). Cs-Beta-OF showed a broad band at around $3000 \mathrm{~cm}^{-1}$, which is assigned to C-H stretching vibration of chloroform on base sites [28]. The asymmetric shape of the band indicates the overlap of at least two bands centering at around 3000 and $2970 \mathrm{~cm}^{-1}$. The former band is assigned to chloroform simply adsorbed on top of a basic framework oxygen atom, and the latter is assigned to chloroform that adsorbed at two points of the oxygen atom and neighboring $\mathrm{Cs}^{+}$(Figure S2) [29,30]. The redshift of the bands compared to gaseous chloroform (3034 $\mathrm{cm}^{-1}$ ) was due to the elongation of the C-H bond by the interaction with base sites on the zeolite [31]. The intensities of these bands were increased along with the dosing pressure (Figure S3). Cs-Beta-CV gave an absorption band at around $3017 \mathrm{~cm}^{-1}$ in a low intensity. Cs-Y showed an absorption band similar to that of Cs-Beta-OF centering at $3000 \mathrm{~cm}^{-1}$. Table 2 shows of the band shift to gaseous chloroform and integrated peak area of the IR bands for Cs-exchanged zeolites. Since the degree of red shift and the peak area are indicative of the strength and the number of base sites on the zeolites, respectively, Cs-Beta-OF and Cs-Y had the similar number of base sites with similar strength. Cs-Beta-CV had only a small number of weak base sites. Obviously, the catalytic activity in TOF is governed by both the number and the strength of base sites, but scarcely affected by the microporous structures. In particular, there is a threshold strength of base sites that can promote the deprotonation of ethyl acetoacetate; Cs-Beta-OF had enough base strength to 
1 promote the deprotonation, while Cs-Beta-CV did not have such strong base sites, as observed in the

2 red shift at $17 \mathrm{~cm}^{-1}$. These results clearly demonstrated that Cs-Beta-OF had a large number of strong

3 base sites owing to the high aluminum content of OSDA-free beta, leading to a high catalytic

4 performance.

According to Sanderson's theory [32], electronegativity $(S)$ of a multi-component material

can be estimated as a function of electronegativity of each element (see Supporting Information). The partial charge of oxygen atom $\left(\delta_{0}\right)$ can be estimated by using Sanderson’s electronegativity [33]. The composition, electronegativity, and partial charge on oxygen atoms calculated by using the reported electronegativity of each element for the Cs-exchanged zeolites are listed in Table 3 [33]. The partial charge on oxygen atoms for Cs-Beta-OF and Cs-Y were estimated to be -0.32 and -0.37 , respectively. Since an electronegative framework oxygen atom can act as a base site, the $\delta_{0}$ is a good index for strength of base sites [29,33,34]. It is noteworthy that Cs-Beta-OF showed a similar IR band shift to Cs-Y in the adsorption of chloroform and showed similar or slightly better catalytic activity than CsY, though Cs-Beta-OF was estimated to have less basic oxygen atoms by Sanderson's theory. Following Sanderson's theory that hypothesize the delocalized electronic properties of each oxygen atom in a material, the negative charge on oxygen atoms becomes larger along with the $\mathrm{Al}$ content (Figure S4). However, physicochemical properties of framework oxygen atoms differ depending on a coordination state and a framework type. Al atoms do not equally occupy T-sites of the framework but preferentially occupy particular T-sites. In a ${ }^{27} \mathrm{Al}$ MAS NMR spectrum, Cs-Beta-OF showed an intense peak at 57 ppm with a small shoulder peak at 54 ppm, whereas Cs-Beta-CV showed a main 
peak at $54 \mathrm{ppm}$ (Figure 5). These two peaks are assigned to $\mathrm{Al}$ atoms at different T-sites, indicating different distributions of $\mathrm{Al}$ atoms between these beta zeolites. In ion-exchange with $\mathrm{Co}^{2+}$, Beta-OF showed a higher Co/Al ratio than Beta-CV (Table S2), demonstrating that Beta-OF had a large number of $\mathrm{Al}$ atoms located close to each other, so called “paired $\mathrm{Al}$ atoms” [11,35]. It is conceivable that the negative charge on oxygen atoms in such structures with locally a high density of $\mathrm{Al}$ atoms would be higher than that predicted by Sanderson's theory and that such highly electronegative oxygen atoms could act as strong base sites, promoting Knoevenagel condensation reactions.

\section{Conclusions}

The Na-form Beta-OF exhibited remarkable ion-exchange capability due to its high $\mathrm{Al}$ content. The $\mathrm{Na}^{+}$cation was able to be exchanged with various cations including multi-valent cations.

For the ion-exchanged Beta-OF, the order of catalytic activity in Knoevenagel condensation was opposite to that of electronegativity. Cs-Beta-OF had strong base sites comparable to Cs-Y and showed a remarkable catalytic activity. The strong base properties and high catalytic activity of Cs-

Beta-OF was attributed to a local high density of Al atoms, which was particular to OSDA-free zeolite beta. Our findings in this work will contribute to the expansion of the application of various OSDAfree zeolites with high $\mathrm{Al}$ contents as well as the improvement of the base catalytic and ion-exchange properties of metal cation-exchanged zeolites.

\section{Acknowledgement}



and Devices”. This work was supported by JSPS KAKENHI Grant Number JP16H06596.

\section{References}

1. B. Xie, J. Song, L. Ren, Y. Ji, J. Li, F.-S. Xiao, Chem. Mater. 20 (2008) 4533-4535.

2. G. Majano, L. Delmotte, V. Valtchev, S. Mintova, Chem. Mater. 21 (2009) 4184-4191.

3. Y. Kamimura, W. Chaikittisilp, K. Itabashi, A. Shimojima, T. Okubo, Chem. Asian J. 5 (2010) 2182-2191.

4. R. Otomo, T. Yokoi, Micropor. Mesopor. Mater. 224 (2016) 155-162.

5. B. Xie, H. Zhang, C. Yang, S. Liu, L. Ren, L. Zhang, X. Meng, B. Yilmaz, U. Müller, F.-S. Xiao, Chem. Commun. 47 (2011) 3945-3947.

6. Y. Kubota, K. Itabashi, S. Inagaki, Y. Nishita, R. Komatsu, Y. Tsuboi, S. Shinoda, T. Okubo, Chem. Mater. 26 (2014) 1250-1259.

7. P. Sazama, B. Wichterlová, Š. Sklenák, V. I. Parvulescu, N. Candu, G. Sádovská, J. Dědeček,

8. Y. Wang, R. Otomo, T. Tatsumi, T. Yokoi, Micropor. Mesopor. Mater. 220 (2016) 275-281.

9. T. De Baerdemaeker, B. Yilmaz, U. Miller, M. Feyen, F.-S. Xiao, W. Zhang, T. Tatsumi, H. Gies,

10. B. Yilmaz, U. Müller, M. Feyen, S. Maurer, H. Zhang, X. Meng, F.-S. Xiao, X. Bao, W. Zhang, 
11. R. Otomo, U. Müller, M. Feyen, B. Yilmaz, X. Meng, F.-S. Xiao, H. Gies, X. Bao, W. Zhang, D. De Vos, T. Yokoi, Catal. Sci. Technol. 6 (2016) 713-721.

12. R. Otomo, T. Yokoi, T. Tatsumi, ChemCatChem, 7 (2015) 4180-4187.

13. M. Ogura, K. Itabashi, J. Dedecek, T. Onkawa, Y. Shimada, K. Kawakami, K. Onodera, S. Nakamura, T. Okubo, J. Catal. 315 (2014) 1-5.

14. L. Xu, C. Shi, B. Chen, Q. Zhao, Y. Zhu, H. Gies, F.-S. Xiao, D. De Vos, T. Yokoi, X. Bao, U.

Kolb, M. Feyen, S. Maurer, A. Moini, U. Müller, W. Zhang, Micropor. Mesopor. Mater. 236 (2016) 211-217.

15. Y. Kobatake, K. Momma, S. P. Elangovan, K. Itabashi, T. Okubo, M. Ogura, ChemCatChem, 8 (2016) 2516-2524.

16. A. Corma, V. Fornes, R. M. Martin-Aranda, H. Garcia, J. Primo, Appl. Catal. 59 (1990) 237-248.

17. U. Meyer, H. Gorzawski, W.F. Hölderich, Catal. Lett. 59 (1999) 201-206.

18. Y. Ono, T. Baba, Catal. Today, 38 (1997) 321-337.

19. S. Saravanamurugan, M. Palanichamy, M. Hartmann, V. Murugesan, Appl. Catal. A, 298 (2006) $8-15$.

20. K.P. Volcho, S. Y. Kurbakova, D. V. Korchagina, E. V. Suslov, N. F. Salakhutdinov, A. V. Toktarev, G. V. Echevskii, V. A. Barkhash, J. Mol. Catal. A, 195 (2003) 263-274.

21. T. Yamashiro, K. Narita, K. Sato, M. Nomura, S. Nakata, J. Jp. Petro. Inst. 53 (2010) 351-354.

22. A. Borgna, S. Magni, J. Sepúlveda, C. L. Padró, C. R. Apesteguía, Catal. Lett. 102 (2005) 15-21. 
1 23. H. Han, M. Liu, F. Ding, Y. Wang, X. Guo, C. Song, Ind. Eng. Chem. Res. 55 (2016) 1849-1858.

2 24. T. Yashima, H. Suzuki, N. Hara, J. Catal. 33 (1974) 486-492.

3 25. R. G. Pearson, Inorg. Chem. 27 (1988) 734-740.

4 26. National Institute of Standards and Technology, USA, Chemistry WebBook. 5 (http://webbook.nist.gov/chemistry/)

$6 \quad$ 27. F. Bordwell, H. Fried, J. Org. Chem. 46 (1981) 4327-4331.

$7 \quad$ 28. J. Lavalley, Catal. Today, 27 (1996) 377-401.

8 29. J. Xie, M. Huang, S. Kaliaguine, React. Kinet. Catal. Lett. 58 (1996) 217-227.

9 30. E. Bosch, S. Huber, J. Weitkamp, H. Knözinger, Phys. Chem. Chem. Phys. 1 (1999) 579-584.

10 31. J. R. Madigan, F. F. Cleveland, J. Chem. Phys. 19 (1951) 119-123.

11 32. R. T. Sanderson, J. Am. Chem. Soc. 105 (1983) 2259-2261.

12 33. W. J. Mortier, J. Catal. 55 (1978) 138-145.

34. D. Barthomeuf, J. Phys. Chem. 88 (1984) 42-45.

35. P. Sazama, E. Tabor, P. Klein, B. Wichterlova, S. Sklenak, L. Mokrzycki, V. Pashkkova, M. Ogura, J. Dedecek, J. Catal. 333 (2016) 102-114. 
Table 1 Composition of ion-exchanged beta and Y zeolites.

\begin{tabular}{|c|c|c|c|c|c|c|}
\hline \multirow{2}{*}{ Sample } & \multirow{2}{*}{$\begin{array}{c}\mathrm{Si} / \mathrm{Al} \\
(-)\end{array}$} & \multirow{2}{*}{$\begin{array}{l}\text { Al content }{ }^{a} \\
(\mathrm{mmol} / \mathrm{g})\end{array}$} & \multicolumn{2}{|c|}{ Cation a,b (mmol/g) } & \multirow{2}{*}{$\begin{array}{c}\text { Ion-exchange }{ }^{c} \\
(\%)\end{array}$} & \multirow{2}{*}{$\begin{array}{l}\text { Base site }^{\mathrm{d}} \\
(\mathrm{mmol} / \mathrm{g})\end{array}$} \\
\hline & & & Metal & Sodium & & \\
\hline Na-Beta-OF & 5.1 & 2.2 & - & 2.3 & - & 0.96 \\
\hline H-Beta-OF & 5.0 & 2.3 & - & 0.03 & - & 0.04 \\
\hline Zn-Beta-OF & 5.1 & 2.2 & 0.73 & 0.27 & 66 & 0.55 \\
\hline Ag-Beta-OF & 5.1 & 2.1 & 1.9 & 0.08 & 90 & 0.06 \\
\hline Cs-Beta-OF & 5.0 & 2.0 & 1.6 & 0.27 & 80 & 1.53 \\
\hline La-Beta-OF & 5.1 & 1.9 & 0.35 & 0.28 & 55 & 0.61 \\
\hline Cs-Beta-CV & 11.9 & 1.0 & 0.26 & trace & 26 & 0.19 \\
\hline Cs-Y & 2.8 & 3.0 & 1.6 & 1.5 & 53 & 0.44 \\
\hline
\end{tabular}

$2 \quad{ }^{a}$ Determined by ICP-AES.

$3 \quad$ b Determined by AAS.

$4 \quad{ }^{\mathrm{c}}$ Ion-exchange degree for $\mathrm{M}^{\mathrm{n}+}$ is defined as $(\mathrm{n} \times$ Metal content $) /(\mathrm{Al}$ content $) \times 100$.

$5 \mathrm{~d}$ The amount of base site determined by $\mathrm{CO}_{2}$-TPD.

6 
Table 2 Base and catalytic properties of Cs-exchanged zeolites.

\begin{tabular}{|c|c|c|c|c|c|c|c|}
\hline \multirow[b]{2}{*}{ Sample } & \multirow[b]{2}{*}{ Composition $^{a}$} & \multirow{2}{*}{$\begin{array}{l}\text { Peak shift }{ }^{b} \\
\qquad\left(\mathrm{~cm}^{-1}\right)\end{array}$} & \multirow{2}{*}{$\begin{array}{c}\text { Peak area } \\
\text { c } \\
\left(\mathrm{cm}^{-1}\right)\end{array}$} & \multirow[b]{2}{*}{$S^{d}$} & \multirow[b]{2}{*}{$\delta_{\mathrm{O}}^{e}$} & \multicolumn{2}{|c|}{ Turnover frequency ${ }^{\mathrm{f}, \mathrm{g}}\left(\mathrm{h}^{-1}\right)$} \\
\hline & & & & & & $\mathrm{ECA}^{\mathrm{h}}$ & $\mathrm{EAA}^{\mathrm{h}}$ \\
\hline Cs-Beta-OF & $\mathrm{Na}_{0.13} \mathrm{Cs}_{0.81} \mathrm{Al}_{1.0} \mathrm{Si}_{5.0} \mathrm{O}_{12.0}$ & -34 & 9.6 & 3.69 & -0.32 & 13.8 & 3.0 \\
\hline Cs-Beta-CV & $\mathrm{H}_{0.74} \mathrm{Cs}_{0.26} \mathrm{Al}_{1.0} \mathrm{Si}_{11.9} \mathrm{O}_{25.8}$ & -17 & 1.5 & 4.14 & -0.23 & 20.0 & $<0.1$ \\
\hline Cs-Y & $\mathrm{Na}_{0.46} \mathrm{Cs}_{0.54} \mathrm{Al}_{1.0} \mathrm{Si}_{2.8} \mathrm{O}_{7.6}$ & -34 & 9.8 & 3.47 & -0.37 & 9.1 & 2.0 \\
\hline
\end{tabular}

$2{ }^{a}$ Determined by ICP-AES and AAS.

$3 \quad$ b IR peak shift in C-H stretching vibration of adsorbed chloroform relative to gaseous molecule.

$4 \quad$ c Integrated peak area of IR band for C-H stretching vibration.

5 d Sanderson's electronegativity.

$6 \quad$ e Partial charge on oxygen atoms.

7 f Turnover frequency was calculated as (mmol of product at $0.5 \mathrm{~h}$ ) / (mmol of cesium in a catalyst) / $0.5 \mathrm{~h}$.

$8 \quad$ g Reaction conditions were identical to those for Figure 3.

$9 \quad$ h TOF for Knoevenagel condensation of benzaldehyde with ethyl cyanoacetate (ECA) and ethyl acetoacetate (EAA). 


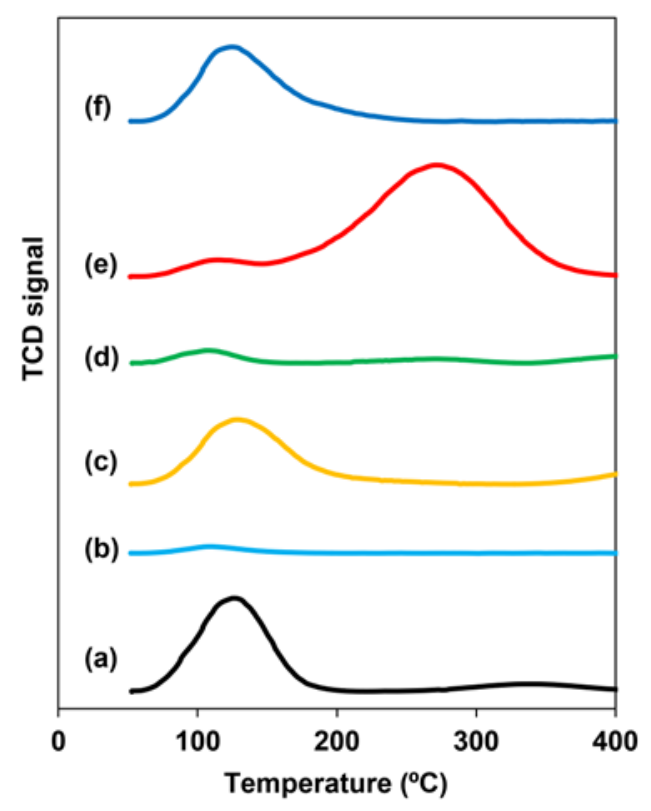

Figure $1 \mathrm{CO}_{2}$-TPD profiles of (a) Na-Beta-OF, (b) H-Beta-OF, (c) Zn -Beta-OF, (d) Ag-Beta-OF, (e) Cs-Beta-OF, and (f) La-Beta-OF. 


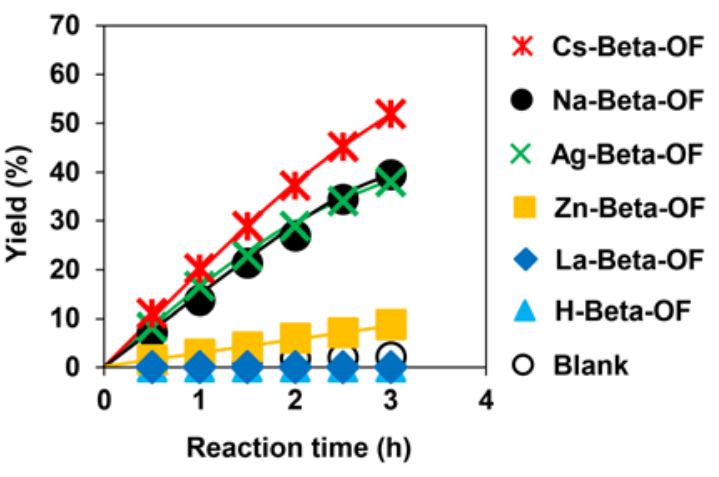

2

3 Figure 2 Catalytic performance of ion-exchanged zeolites for in Knoevenagel condensation of 4 benzaldehyde with ethyl cyanoacetate. Reaction conditions, catalyst, $50 \mathrm{mg}$; benzaldehyde, $5 \mathrm{mmol}$;

ethyl cyanoacetate, $5 \mathrm{mmol}$; DMSO $25 \mathrm{ml}$; temperature, $60{ }^{\circ} \mathrm{C}$. 

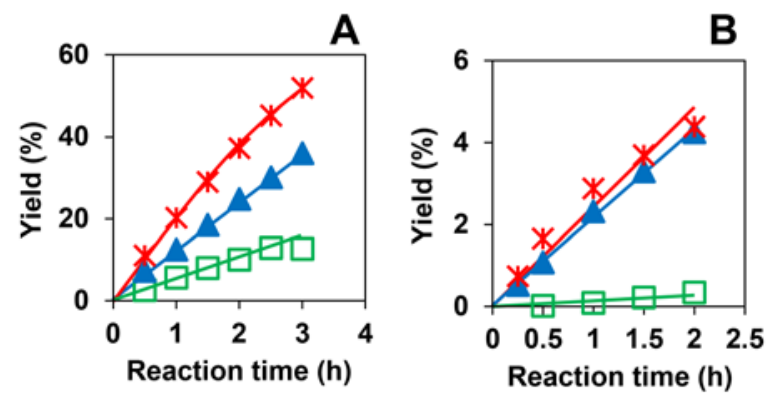

* Cs-Beta-OF

$\Delta$ Cs-Y

$\square$ Cs-Beta-CV

3 Figure 3 Catalytic performance of Cs-exchanged zeolites in Knoevenagel condensation of 4 benzaldehyde with (A) ethyl cyanoacetate and (B) ethyl acetoacetate. Reaction conditions, catalyst, $550 \mathrm{mg}$; benzaldehyde, $5 \mathrm{mmol}$; ethyl cyanoacetate or acetoacetate, $5 \mathrm{mmol}$; DMSO $25 \mathrm{ml}$; 6 temperature, 60 and $100{ }^{\circ} \mathrm{C}$ for ethyl cyanoacetate and acetoacetate, respectively. 


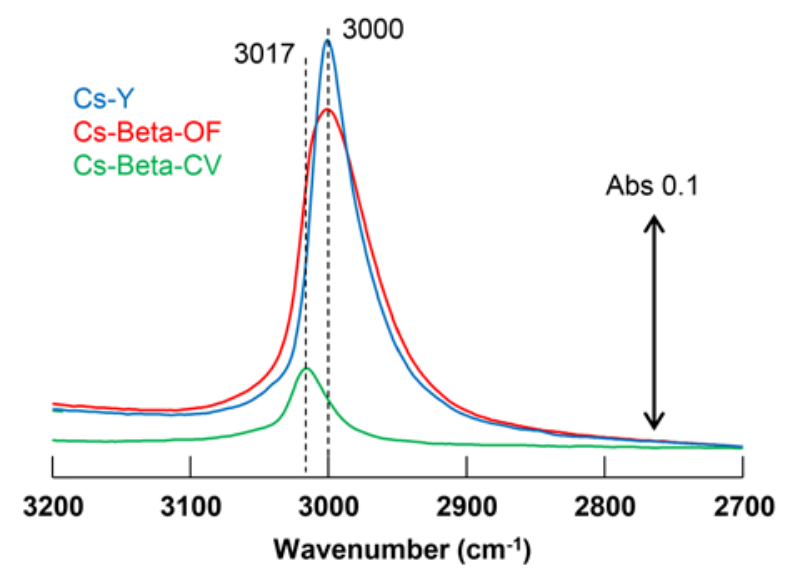

2

3 Figure 4 IR spectra of chloroform adsorbed on Cs-exchanged zeolites at the dosing pressure of 50

Pa. 


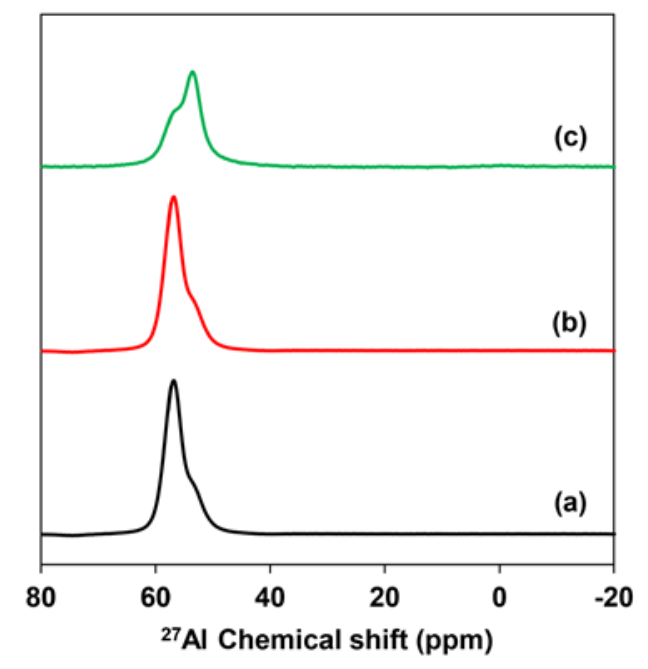

1

2

3 Figure 5 Solid-state ${ }^{27} \mathrm{Al}$ MAS NMR spectra of (a) Na-Beta-OF, (b) Cs-Beta-OF, and (c) Cs-Beta4 CV. 


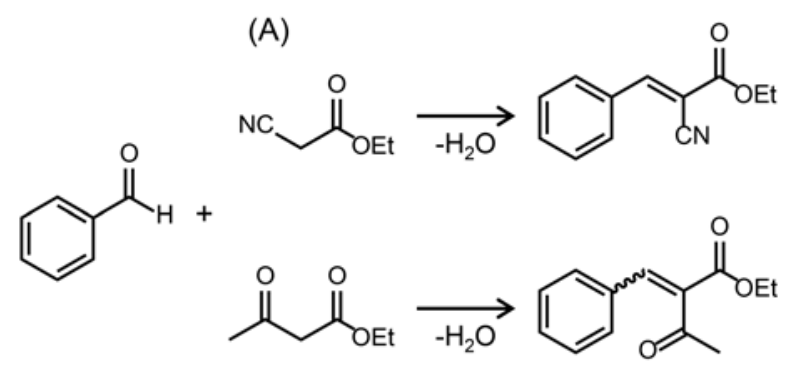

1

3 4

5

(B)

Scheme 1 Knoevenagel condensation of benzaldehyde with (A) ethyl cyanoacetate or (B) ethyl acetoacetate. 